\title{
Planejamento Dinâmico, Plonejamento com Liberdade
}

JOÃo PAULO dOS REIS VELLOSO

Ministro do Planejamento e Coordenação Geral

\begin{abstract}
"O camelo é um cavalo feito por planejadores." (Auto-análise de um planejador cubano.)
\end{abstract}

Em pronunciamento na sessão de abertura do VIII Congresso Interamericano de Planejamento, em Salvador, pareceu-nos oportuno avaliar, franca e objetivamente, os caminhos percorridos pelo planejamento em terras abaixo do Rio Grande.

Um balanço da experiência de programação; na América Latina e outras áreas subdesenvolvidas, ao longo dos anos 50 e 60 , permite a constatação de que, de um lado, o planejamento do desenvolvimento nacional constitui, hoje, prática virtualmente universal. É generalizada a convicção da importância e necessidade do planejamento, como patrimônio a preservar e consolidar. De outro lado, existe, em alguns países, considerável frustração em relação aos resultados dos planos aprovados, por problemas ligados à sua formulação ou à sua implementação.

Ao mesmo tempo, o tipo de problemas que a América Latina vai enfrentar, numa década em que sòmente a aceleraçăo do desenvolvimento econômico e social poderá aliviar as tensões sociais e politicas, está exatamente a exigir soluções que dependem de planejamento em escala crescente. Mas de um planejamento menos mecanicista e mais orgânico do que tem sido o padrão de desempenho dos últimos anos.

\section{PLANEJAMENTO \\ E EXECUÇĀO}

E importante recordar os principais obstáculos e problemas que o planejamento tem enfrentado, em áreas subdesenvolvidas.

Primeiro: no aspecto de formulação, o fato de que os determinantes essenciais do desenvolvimento são dificilmente suscetíveis de planejamento, pelo menos no sentido do planejamento econômico e físico que habitualmente se realiza.

E sabido que a decisão de desenvolver-se, em um pais, é problema de natureza eminentemente política, e não de sentido econômico ou técnico. Por outro lado, a capacidade de desenvolver-se constitui problema eminentemente cultural - no sentido socioIógico. Desenvolvimento significa a 
construção de uma sociedade, e, nesse processo criador, estão envolvidas as atitudes e valôres sociais, as instituições econômicas, sociais e politicas, a cultura nacional, globalmente.

Daí por que o recente Simpósio de Belágio, promovido pela $\mathrm{OECD}$, analisando o avanço metodológico na formulação dos planos, distinguiu os três niveis de planejamento: o operacional, o estratégico e o normativo; e, ao lado dos modelos mecanicistas, cuidou dos "modelos de ação humana" ("human action models"), preocupados, globalmente, com a "organização do progresso" e suscetiveis de modificar o environment físico e cultural. Segundo a Declaração de Belágio, faz-se necessário "planejar sistemas em seu conjunto, apreender a totalidade dos fatôres envolvidos e intervir na sua estrutura para alcançar operação mais integrada."

Segundo: a tendência, observada em vários paises, a um hiato entre a formulação e execução dos planos, confiando-se a elaboração do planejamento global e setorial a um órgão específico de planejamento, e deixando-se a execução por conta da máquina administrativa tradicional. Rompe-se, desta forma, o caráter eminentemente integrado e contínuo do processo de planejamento, que compreende os estágios de formulação, execução, acompanhamento e revisão de planos, com a indispensável realimentação (fieed back).

É útil dispor de um órgão central de planejamento, mas suas funções devem ser dentro da orientação superior do Chefe da Nação, a visão global (isto é, não setorial e não regionalizada) do plano, a integração dos programas se- toriais e regionais e a coordenação do sistema de acompanhamento. A elaboração dos programas setoriais e regionais deve ser de responsabilidade dos Ministérios respectivos, naturalmente de forma consistente com as diretrizes do plano global e em estreita articulação com o órgão central do sistema. Só assim se evitará o divórcio entre formulaçăo e execução.

Trata-se, pois, de estabelecer um processo de planejamento, institucionalizado e permanente, embutido no próprio mecanismo de implementação e permitindo, inclusive, acompanhar a execução dos principais programas e projetos.

Tal mecanismo, e não o documento denominado plano, é que deve constituir a preocupação essencial do Govêrno.

Terceiro: a tendência a uma preocupação excessiva com a metodologia e com o instrumental do planejamento, elevados a um alto grau de refinamento (modelos econométricos, testes de consistência, shadow prices, pesquisa operacional), numa espécie de arte pela arte. Ora, o planejamento deve ser, essencialmente, o instrumento de aperfeiçoamento da política de desenvolvimento, em forma quantitativa. Como observa Rosenstein-Rodan: "Programação é apenas uma outra palavra para uma política econômica racional, deliberada, consistente e coordenada".

Quarto: a preocupação exclusiva, não raro, nos planos, com os aspectos econômico e físico. É nesse sentido que se tem concentrado o esfôrço de aperfeiçoamento da programação, esquecendo-se que "um plano consistente não garante melhor implementa- 
ção do que um plano inconsistente." 0 esfôrço de aperfeiçoamento deve ser dirigido principalmente à análise dos problemas administrativo-institucionais e às resistências políticas que possam constituir obstáculo à materialização dos objetivos do plano e dos seus projetos principais.

"O problema é menos o de produzir um documento analiticamente elegante e internamente consistente. A tarefa é mais de disseminar o hábito de planejamento, de estabelecer o cálculo econômico racional como a norma comum para a tomada de decisão, e de ter isso aceito por aquêles responsáveis por tomar decisōes. É um problema de organização e de administração gerencial."

Quinto: as distorçōes comuns à própria atuação do Govêrno que, freqüentemente, caminha em demasia para a execução direta de tarefas suscetíveis de mais eficiente desempenho pela iniciativa privada, negligenciando funções próprias suas, insuscetiveis de delegação, como a seleção de prioridades, a correção de distorções no mecanismo de preços, os incentivos ao setor privado, a qualificação dos recursos humanos, as decisões políticas básicas para a política de desenvolvimento.

\section{CONCEPÇÃO DINÂMICA DO PLANEJAMENTO BRASILEIRO}

Como a necessidade do planejamento tende a aumentar, ante a gravidade e complexidade crescente que o desafio do subdesenvolvimento apresenta, na sociedade pós-industrial que se avizinha, será preciso superar aquêles problemas. Isso exige um planejamento ágil, leve e menos exaustivo; dinâ- mico, contínuo e menos mecanicista; orgânico, sem a dicotomia de elaboração e implementação.

Sistemàticamente, a partir de 1964 , tem o Brasil, ao lado de outros países latino-americanos, realizado um estôrço contínuo de implantação, dêsse planejamento objetivo e criador. Planejamento que deverá ser aperfeiçoado continuamente, mas que tem apresentado resultados no sentido de consideràvelmente melhor desempenho dos programas de govêrno; e que, ao nosso ver, deve exercer as seguintes funçōes básicas:

1) A racionalização das decisões do Govêrno, orientada no sentido do aperfeiçoamento da execução dos programas, com 0 estabelecimento de prioridades setoriais definidas e, para a atuação direta do setor público, de critério de seleção de projetos e realização de investimentos.

2) A modernização da máquina governamental, para aumento de eficiência na formulação e execução de programas; e a transformação das estruturas sociais e econômicas e das atitudes sociais que constituem fator limitativo do desenvolvimento.

3) A compreensão de que o segrêdo do crescimento está no estímulo à capacidade criadora das emprêsas, dos trabalhadores e do setor público. E o entendimento de que o crescente papel do Govêrno não deve manifestar-se sob a forma de sua expansão, quantitativa, nem conduzir à estatização, para que não se crie um sistema eivado de inconsistêncla interna, tendente a fazer secar a fonte de progresso no regime de economia descentralizada.

4) A preocupação dirigida principalmente aos resultados, ou seja, à con- 
secução dos objetivos do plano. Evitando tentar colocar a realidade econômica e social numa camisa de fôrça, cabe utilizar flexivelmente as políticas instrumentais, sem apêgo cego às soluções de livros-texto, que podem partir de pressupostos inexistentes ou ignorar aspectos institucionais relevantes; e sem incorrer no primarismo de considerar irrelevante a teoria econômica, numa espécie de indução às avessas, segundo a qual o que é válido em outras nações é necessàriamente não válido em nosso país.

5) O planejamento com liberdade, e até mesmo o planejamento para a liberdade, dentro de uma sociedade progressista e aberta. Progressista, para fortalecer o poder de competição nacional e permitir ao país participar do potencial de crescimento representado pelo progresso tecnológico em explosão de ritmo; e aberta, para assegurar a descentralização do poder econômico e a disseminação de oportunidades, indispensáveis à auto-sustentação do processo de desenvolvimento numa economia democrática.

\section{PROBLEMAS BÁSICOS DA AMERICA LATINA}

Êsse planejamento dinâmico irá defrontar-se, na próxima década, com os temas básicos do desenvolvimento latino-americano, e principalmente dos países, entre nós, industrialmente avançados.

Destaque-se, antes de tudo, a importância de uma estratégia de desenvolvimento mais voltada para a expansão do mercado interno e o acesso aos mercados externos, agora que perdeu substância o processo industrial de substituição de importações. Estratégia baseada na integração de crescimento industrial e crescimento agrícola, superando os preconceitos contra a agricultura e sabendo usar o progresso industrial para modernizar essa mesma agricultura e a infra-estrutura econômica. Estratégia que se ocupe diretamente da superação de barreiras à expansão das vendas da América Latina no comércio internacional.

Há necessidade de definir uma politica tecnológica nacional, implicando a aceleração da transferência de tecnologia para o pais, assim como forte componente de elaboração tecnológica própria, para gradativa absorção da engenharia de processo e de produto e para a solução de problemas tecnológicos próprios, na agricultura, indústria e mineração.

Para tirar partido dos recursos humanos disponíveis, dever-se-á construir uma estrutura integrada de Educação, Ciência-Tecnologia e Indústria. Isso significa um sistema educacional bem disseminado, sem preconceitos contra o trabalho - contra qualquer espécie de trabalho - e que integre o individuo na sociedade moderna, amante do esfôrço, da inteligência aplicada, do espirito criador.

Em primeiro plano, figura ainda o problema do planejamento das regiões metropolitanas - no caso brasileiro, especialmente o Grande São Paulo e o Grande Rio, com perspectiva de população até 1980, da ordem de 13 e 11 milhões, respectivamente. Esse desafio não tem sentido simplesmente técnico, de desenvolvimento urbano ou de contrôle do grau de poluição do $a r$ e da água: O problema é global, envolvendo o próprio tipo de civilização em que vivemos, pois se trata de provar ser 
possível a civilização industrial e pósindustrial, sem contínua deterioração da qualidade da vida, nas suas dimensões econômica, social, urbana e ambiental.

\section{O DESENVOLVIMENTO AUMENTA A LIBERDADE DO HOMEM}

Todo o esfôrço de planejamento que se vem realizando, mundo afora, torna - desenvolvimento como objetivo primordial.

Se o que interessa é o destino do homem, resta saber se o crescimento econômico, medido pelo aumento da renda per capita, é realmente desejável.

Em recente peça teatral, Art Buchwald fala de um principado no Tibet, ou coisa parecida, cujo monarca resolveu solicitar assistência internacional para o progresso de seu país. A missåo seria propor um acôrdo militar ou algo dessa ordem. O representante de uma agência internacional sugeriu medidas para elevar o padrão de vida do povo. Curioso, o monarca então indagou: "Mas por que elevar o padrão de vida do povo?" Meio desconcertado, o homem da ajuda financeira pôde apenas responder: "Bem, é - que geralmente se faz com o padrão de vida."

Estamos, aqui, diante dessa indagação crítica: por que o crescimento econômico? Resta saber se não estaremos, na perseguição dêsse objetivo em que, pràticamente, se concentram as energias dos paises subdesenvolvidos, tomando o bonde errado. Por que a preocupação dominante com o aumento da renda $\theta$, como condição indispensável, com ○ progresso tecno- lógico, se para isso vamos abrir mão de valôres éticos e espirituais, submeter o indivíduo à ameaça do Estado onipresente, a sociedade ao perigo do "nôvo estado industrial" à la Galbraith, as unidades econômicas de origem familiar ao risco de absorção pela grande emprêsa, em busca de economias de escala?

Êsses receios se traduzem, para o mundo atual, na colocação de Ozbekhan: ... "Nosso futuro não pode ser concebido senão sob a forma de uma nova e perigosa realidade, criada pelo crescimento populacional, a mudança e a aceleração tecnológica, a reversão das relaçōes econômico-metabólicas entre o homem e a natureza, e a emergência do que mais e freqüentemente está sendo denominado de "idade pósindustrial." E tudo isso que cria as complexidades e incertezas de que falamos... Por tudo isso eu quero dizer êsse nôvo mundo que nós, a geração que está montada na crista da onda da mudança, estamos achando tăo grande, tão diferente, tão estranho e tão inquietador."

A defesa do crescimento econômico resulta, primeiro, do simples fato de que a sociedade ocidental deseja o bem-estar material, a elevação continua dos padrōes de vida. Mais importante, como observa Lewis, é que o crescimento econômico amplia o grau de escolha $e$, conseqüentemente, aumenta a liberdade do homem.

Liberdade, pelo contrôle sôbre a natureza e, por isso, sôbre a fome, a doença, a morte, dentro da idéia, tomada axiomàticamente, de que o homem prefere a vida à morte. Liberdade para escolher entre mais renda e mais lazer, ou ambos simultâneamente, pela 
maior produtividade alcançada. Liberdade para enfrentar os desafios éticos do nosso tempo - o da garantia de padrão de vida mínimo satisfatório a cada indivíduo, e o da possibilidade de acesso gradual dos países em desenvolvimento à sociedade desenvolvida.

Liberdade, ainda, para garantir a estabilidade social e política, em face das tensões provocadas, nos nossos paises, pela comparação com o rápido aumento de renda dos países desenvolvidos. Porque, como é sabido, o inimigo da estabilidade não é a descrença e a miséria, mas o descompasso entre a exacerbação das aspiraçōes e o aumento efetivo da disponibilidade de bens e serviços. Por essa razão, $\theta$ ante $o$ crescimento demográfico observado, é preciso não apenas crescer, mas crescer a taxas superiores às do passado.
Por outro lado, se a sociedade ocidental deseja a prosperidade material, ela não se satisfaz com a prosperidade material apenas, como o revelam os conflitos entre estudantes e trabalhadores, nos Estados Unidos, e os levantes estudantis nas nações ricas, em fase recente.

Faz-se mister, conseqüentemente, ao longo do processo de desenvolvimento, fazer mais do que a simples expansão da renda, tendo a noção clara da sociedade que se deseja construir, capaz de conciliar a tecnologia e o humanismo moderno, dar ao grande número participação nos resultados do progresso, defender a identidade nacional, preservar a qualidade da vida. Para a definição de sociedade objetivada, cabe papel de destaque à universidade e às instituições políticas.

"Jornal do Brasil", 20-9-70 